\title{
Avaliação histomorfométrica e da proliferação celular em úlceras de córnea superficiais, induzidas em coelhos, após o uso de colírio de Citrus lemon
}

[Histomorphometry evaluation and cellular proliferation in superficial corneal ulcer, induced in rabbits, after using eyedrops of Citrus lemon]

\author{
C.S. Perches ${ }^{1}$, C.H. Pellizzon ${ }^{2}$, J.J.T. Ranzani ${ }^{1}$, C.R. Padovani ${ }^{2}$, N.B. Merlini ${ }^{1}$, M.G. Sereno ${ }^{3}$, \\ J.F. Fonzar ${ }^{1}$, C.V.S. Brandão ${ }^{1 *}$
}

${ }^{1}$ Faculdade de Medicina Veterinária e Zootecnia - Universidade Estadual Paulista - Botucatu, SP

${ }^{2}$ Instituto de Biociências - Universidade Estadual Paulista - Botucatu, SP

${ }^{3}$ Médica veterinária autônoma

\begin{abstract}
RESUMO
O objetivo do presente estudo foi avaliar e comparar, por meio de histomorfometria e imuno-histoquímica para PCNA (Antígeno Nuclear de Proliferação Celular), o processo de reparação corneal de úlceras superficiais induzidas em coelhos e tratadas com colírios de óleo essencial de Citrus lemon (CL). Foram utilizadas 40 fêmeas da espécie leporina, constituindo-se quatro grupos experimentais de 10 animais cada. Todos os animais foram submetidos à indução da úlcera superficial experimental por meio da aplicação tópica de n-heptanol. Em dois grupos foram instilados colírios à base de óleo essencial de Citrus lemon, em diferentes concentrações, sendo 3\% (GL3) e 5\% (GL5). Outro grupo foi tratado com Tween 80 8\% (GT), que é o diluente utilizado na produção dos colírios de CL; o grupo controle (GC) recebeu apenas substituto da lágrima. Todos os colírios foram aplicados quatro vezes ao dia. Os grupos experimentais foram distribuídos em dois subgrupos, com cinco animais cada, de acordo com os períodos finais de avaliação. O primeiro subgrupo (M1) foi avaliado após 24 horas e o segundo (M2), após cinco dias. Nas comparações entre os momentos iniciais e finais, os grupos tratados com substituto da lágrima, Tween 80 $8 \%$ e colírio à base de óleo essencial de Citrus lemon 5\% promoveram aumento na espessura epitelial na periferia da córnea e maior percentual de proliferação celular. Não houve diferença de celularidade entre os tratamentos. Os colírios à base de óleo essencial de Citrus lemon, nas diferentes concentrações, promoveram a reepitelização corneal, sem causar lesões adicionais ao epitélio ou estroma corneal, podendo ser utilizado na superfície ocular.
\end{abstract}

Palavras-chave: limão-siciliano, córnea, úlcera, PCNA, histologia

\begin{abstract}
The aim of this study was to evaluate and compare through histomorphometry and immunohistochemistry for PCNA (Proliferating Cell Nuclear Antigen), the repair process in superficial corneal ulcers induced in rabbits and treated with eyedrops of Citrus lemon (CL) essential oil. Fifty female rabbits were used and divided into 4 experimental groups of 10 animals each one. Every animal underwent induction of experimental superficial ulcer by topical application of n-heptanol. Three groups were treated with eyedrops of Citrus lemon essential oil in two different concentrations: 3\% (GL3) and 5\% (GL5). Another group was treated with Tween 80 8\% (GT), which is the solvent used in the production of eyedrops of CL; the control group (CG) received only tear substitute. All eyedrops were applied four times daily. The experimental groups were divided into two subgroups with five animals in each one, according to the final evaluation periods. The first subgroup (M1) was evaluated after 24 hours and the second (M2) after 5 days. In the comparison between the initial and final moments, the groups treated with tear substitute, Tween 80 8\% and eyedrops of Citrus lemon essential oil 5\% had an increase in epithelial thickness at the
\end{abstract}

Recebido em 4 de setembro de 2014

Aceito em 7 de julho de 2015

*Autor para correspondência (corresponding author)

E-mail: valeriasb@fmvz.unesp.br 
periphery of the cornea and a higher percentage of cell proliferation. There was no difference in cellularity between treatments. The eyedrops of Citrus lemon essential oil, at different concentrations, promoted corneal reepithelialization without causing further injury to the epithelium and corneal stroma, so they can be used on the ocular surface.

Keywords: sicilian lemon, cornea, ulcer, PCNA, histology

\section{INTRODUÇÃO}

A ceratite ulcerativa é caracterizada por lesões erosivas corneais com perda de epitélio e exposição do estroma. Os principais agentes causais são os traumas, defeitos palpebrais, desordens do sistema lacrimal, além de infecções por fungos, bactérias e/ou vírus (Gilger et al., 2007).

O epitélio apresenta grande capacidade de regeneração; assim, após uma lesão, as células epiteliais entram em mitose e deslizam em direção ao centro da lesão, preenchendo o defeito. Se todo o epitélio corneal for removido, o estroma será recoberto por deslizamento de células do epitélio do limbo, sendo completamente reposto em duas semanas (Gilger et al., 2007).

Os óleos essenciais são extraídos de várias plantas e conhecidos por suas propriedades antissépticas e medicinais de sua fragrância (aromaterapia). São usados na preservação de alimentos, como antimicrobianos, analgésicos, sedativos, anti-inflamatórios, espasmolíticos e agentes anestésicos locais, entre outros (Bakkali et al., 2008).

Citrus lemon Burm. f. pertence à família Rutaceae e é popularmente conhecido no Brasil como limão-siciliano (Aloisi et al., 2002; Cecarelli et al., 2004). Os seus maiores componentes são dois monoterpenos: limoneno e $\beta$-pineno, sendo o primeiro o principal constituinte dos óleos essenciais de citrus (Rozza et al., 2011). Esse produto natural possui propriedades biológicas, tais como efeito bactericida (Fisher e Phillips, 2006) e atividades antiulcerogênicas (Lewis e Hanson, 1991).

O tratamento de úlceras gástricas de ratos com Citrus lemon promoveu aumento na proliferação celular, vascularização e de células importantes na resposta às lesões. Adicionalmente, foi capaz de evitar a formação da úlcera gástrica, por estímulo à produção de muco, efeitos antioxidantes e anti-inflamatórios (Rozza et al., 2011). Moraes et al. (2009) obtiveram resultados semelhantes com o uso de limoneno como protetor da mucosa gástrica.

O presente estudo teve como objetivo avaliar, por meio de histomorfometria e imunohistoquímica para PCNA (Antígeno Nuclear de Proliferação Celular), o processo de reepitelização corneal de úlceras superficiais, induzidas experimentalmente em coelhos, frente ao uso de colírios à base de óleo essencial de Citrus lemon, nas concentrações 3\% e 5\%.

\section{MATERIAIS E MÉTODOS}

Foram utilizadas 40 fêmeas da espécie leporina (Oryctolagus cuniculus), pertencentes ao grupo genético Botucatu, com idade variando entre $90 \mathrm{e}$ 180 dias e peso entre 2 e $4 \mathrm{~kg}$. Os coelhos foram fornecidos pelo biotério central da UNESP, Campus de Botucatu.

Os animais foram submetidos aos exames clínicos e oftalmológicos de rotina com auxílio de lâmpada de fenda portátil (Kowa SL-15®), bem como ao teste de Schirmer (Ophthalmos, Brasil), à tonometria (Tono Pen $\AA$, MedTronic) e à oftalmoscopia direta (Oftalmoscópio direto, Welch Allyn). Após o procedimento cirúrgico, os coelhos foram identificados e mantidos em gaiolas individuais com água potável e ração comercial (Coelhil S, Socyl) ad libitum.

Os procedimentos experimentais desenvolvidos seguiram as normas da Association for Research in Vision and Ophthalmology (ARVO) e foram submetidos à Câmara de Ética em Experimentação Animal da Faculdade de Medicina Veterinária e Zootecnia - UNESP Campus de Botucatu. Protocolo número 174/2008 CEEA.

O óleo essencial de Citrus lemon (Citrus lemon, Ferquima) foi diluído, no momento do seu uso, em solução de Tween 80 (Polissorbato, Labsynth) a $8 \%$, a fim de se obterem as 
concentrações de $3 \%$ e $5 \%$, constituindo, desse modo, os respectivos colírios. O pH da solução foi ajustado em 7,2, adicionando-se ácido clorídrico (quando necessária a diminuição do $\mathrm{pH}$ ) ou hidróxido de sódio (quando necessário o aumento do $\mathrm{pH}$ ). As soluções foram preparadas em capela de fluxo lamelar unidirecional, estocadas à temperatura de $4^{\circ} \mathrm{C}$, protegidas da luz e utilizadas por até cinco dias.

A composição do óleo essencial de Citrus lemon utilizado no experimento apresentou o limoneno como seu principal componente, representando $70,75 \%$, seguido pelo $\beta$-pineno com $13,19 \%$ e pelo $\gamma$-terpineno com $9,19 \%$.

Os 40 animais foram distribuídos de forma igualitária, aleatoriamente, em quatro grupos experimentais, designados Grupo Controle (GC), Grupo Tween 80 8\% (GT) e dois grupos de colírios à base de Citrus lemon (GL), nas concentrações 3\% (GL3) e 5\% (GL5).

No GC, foi instilado colírio substituto da lágrima (Lacrima plus ${ }^{\circledR}$, Alcon). No GT, os animais foram tratados com colírio de Tween 80 na concentração 8\%. E os grupos GL3 e GL5 foram tratados com colírio à base de óleo essencial de Citrus lemon, nas concentrações $3 \%$ e $5 \%$, respectivamente.

Os animais foram anestesiados com quetamina (Dopalen ${ }^{\circledR}, \quad$ Vetbrands) $\quad(20 \mathrm{mg} / \mathrm{kg}) \quad$ via intramuscular (IM), associada à xilazina (Anasedan ${ }^{\circ}$, Vetbrands) $\quad(1 \mathrm{mg} / \mathrm{kg}) \quad$ IM e à morfina (Dimorf $\AA$, Cristália) $(0,5 \mathrm{mg} / \mathrm{kg}) \quad \mathrm{IM}$. Adicionalmente, foi feita a anestesia tópica ocular por meio de utilização de colírio anestésico (Anestalcon $\AA$, cloridrato de proximetacaína $0,5 \%$, Alcon).

Os procedimentos operatórios foram realizados com auxílio de microscópio cirúrgico (Karl Kaps, modelo SOM 62 Standard, Alemanha) após antissepsia utilizando solução de polivinilpirrolidona (Iodo antisséptico aquoso, Brasiliquidos Produtos Farmacêuticos) a 1:50 e colocação de panos fenestrados oftálmicos estéreis. A fixação mecânica das pálpebras foi feita com blefarostato Barraquer infantil. Para a indução da úlcera corneal, uma haste de algodão foi embebida em n-heptanol e aplicada sobre a córnea a partir do limbo, de forma centrípeta, mantendo o contato do álcool com a córnea durante 3 minutos. A remoção do epitélio foi realizada com uma haste de algodão seca e, posteriormente, a superfície ocular foi lavada com $60 \mathrm{ml}$ de solução fisiológica estéril a $0,9 \%$ para a remoção dos debris e álcool remanescentes (Sampaio et al., 2006).

No pós-cirúrgico imediato e a cada 12 horas, foi administrado, em todos os animais, o antiinflamatório meloxicam (Movatec $\AA$, Boehringer Ingelheim) $(0,2 \mathrm{mg} / \mathrm{kg})$, por via subcutânea (SC), além de morfina (Dimorf ${ }^{\circ}$, Cristália) $(2 \mathrm{mg} / \mathrm{kg}$ ) $\mathrm{SC}$, durante três dias, visando maximizar o conforto pós-operatório.

Os animais foram medicados com os colírios, de acordo com o seu grupo experimental, quatro vezes ao dia, iniciando-se o tratamento logo após a recuperação anestésica. $\mathrm{Na}$ região ocular, foram feitas limpezas diárias das pálpebras, quando necessário, com solução salina a $0,9 \%$ (Solução Fisiológica $\mathrm{NaCl} \quad 0,9 \%$ 250mL, Med Flex), até o final do período de avaliação de cada animal.

Todos os grupos foram divididos em dois subgrupos constituídos por cinco animais cada, de acordo com o seu período final de avaliação, ou seja, M1, avaliados 24 horas pós-cirurgia (dia 1) e M2, no quinto dia pós-operatório.

No final do período de avaliação de cada subgrupo, os animais foram eutanasiados, após anestesia com acepromazina (Acepran ${ }^{\circledR}$ 0,2\%, Univet) $(1,5 \mathrm{mg} / \mathrm{kg})$ e quetamina (Dopalen $\AA$, Vetbrands) $(20 \mathrm{mg} / \mathrm{kg})$ via intramuscular, seguida pela administração intravenosa de tiopental (Thiopentax ${ }^{\circledR}$, Cristália) $(25 \mathrm{mg} / \mathrm{kg})$ e de cloreto de potássio 19,1\% (Cloreto de potássio 19,1\%, Farmace) $(2 \mathrm{~mL} / \mathrm{kg})$. Em seguida, procedeu-se à enucleação do olho operado.

O bulbo ocular foi fixado em formaldeído $10 \%$ (Formol solução 10\%, Indústria Farmacêutica Rioquímica Ltda.) durante 48 horas e, a seguir, fixado em solução de álcool a 70\% (Álcool Zulu absoluto 99,3․ INPM/Companhia Nacional do Álcool). As córneas foram isoladas, processadas para a inclusão em parafina e os cortes histológicos, corados pelo método de hematoxilina/eosina (HE) (Corantes Merck).

Para a análise da celularidade, foi utilizado o microscópio Leica $\mathrm{DM} \AA$ acoplado com o 
software de captura de imagens Leica QWin Standard Versão 3.5.0. Foram capturadas 10 imagens de cada corte histológico, que foram posteriormente analisadas, de forma quantitativa, no programa AVSoft BioView 4®. Para se obter a celularidade, foram contadas células epiteliais, do estroma (ceratócitos) e células inflamatórias (neutrófilos, histiócitos, linfócitos e eosinófilos). Além disso, também foi contado manualmente o número total de células epiteliais encontradas nesses dez cortes histológicos.

A análise morfométrica também foi realizada utilizando-se o analisador de imagens Leica QWin Standard Versão 3.5.0. para medições manuais. $\mathrm{Na}$ análise morfométrica, avaliou-se a espessura do epitélio corneal, que foi mensurado em três diferentes regiões, sendo a medida periférica referente ao epitélio localizado na periferia da córnea e a medida central, na região central da córnea. A medida denominada ponto médio foi obtida na região entre as medidas periférica e central. Foram realizadas dez medidas de cada região, sendo sua média considerada como a espessura final.

Para a avaliação da proliferação celular, foi realizada imuno-histoquímica para PCNA (Proliferating Cell Nuclear Antigen, Novocastra Laboratories Ltda.), marcador de divisão celular, segundo a técnica abaixo descrita.

Após a inclusão das córneas em parafina, foram realizados cortes por microtomia (3 micrômetros) e aplicados sobre lâminas. Em seguida, estas foram desparafinizadas, reidratadas e destinadas à imuno-histoquímica com método de revelação para peroxidase. $\mathrm{O}$ bloqueio de reação inespecífica foi feito com $\mathrm{H} 2 \mathrm{O} 2$ e leite desnatado a $1 \%$; para a recuperação antigênica, utilizou-se tampão citrato aquecido. As amostras foram incubadas com anticorpo específico, anti PCNA, em solução de bloqueio (leite desnatado 1\%) por duas horas. Posteriormente, as amostras foram lavadas em tampão fosfato $(0.01 \mathrm{~mol} / \mathrm{L}, \mathrm{pH} 7.4)$ e incubadas em anticorpo secundário (Super ABC Kit Universal, Easy Path) e revelado com o AvidinaBiotina associado com 3-3`diaminobenzina tetrahydrochloride (DAB, Sigma).
As lâminas foram analisadas no microscópio Leica DM acoplado com o software de captura de imagens Leica QWin Standard Versão 3.5.0.; foram capturadas dez imagens de cada amostra; as células epiteliais totais e as marcadas para PCNA foram contadas manualmente, obtendo-se a porcentagem de células epiteliais em divisão.

A análise estatística foi realizada utilizando-se a técnica da análise de variância não paramétrica (histomorfometria e PCNA) e paramétrica (celularidade), para o modelo de medidas repetidas em grupos independentes, com nível de $5 \%$ de significância $(\mathrm{P}<0,05) \quad$ (Johnson e Wichern, 2002). Para a avaliação estatística do número total de células epiteliais, foi utilizada a técnica de análise de variância não paramétrica para o modelo com dois fatores, complementada com o teste de comparações múltiplas de Dunn, considerando o nível de $5 \%$ de significância (Zar, 2009).

\section{RESULTADOS}

A avaliação das lesões corneais mostrou mediana da espessura epitelial na região periférica da córnea maior nos grupos tratados com colírio de Citrus lemon, tanto no primeiro quanto no segundo momento de avaliação (Tab. 1). No quinto dia de tratamento, a mediana da espessura aumentou em todos os grupos, tanto na região periférica quanto no ponto médio. Entretanto o GT foi o único grupo que mostrou mediana aumentada no centro da córnea (Tab. 1). Houve aumento na celularidade (células epiteliais, estromais e inflamatórias) após 5 dias de tratamento, sem diferença entre os grupos. As células inflamatórias derivadas do processo de cicatrização foram similares em todos os grupos.

O estroma encontrava-se íntegro, nos dois momentos de avaliação, em todos os cortes analisados (Fig. 1).

$\mathrm{Na}$ avaliação do número total de células epiteliais, notou-se aumento significativo da quantidade de células epiteliais nos grupos GC, GT e GL5, do M1 em relação ao M2 (Tab. 2). 


\section{Perches et al.}

Tabela 1. Mediana, valores mínimos e máximos da espessura $(\mu \mathrm{m})$ das regiões do epitélio da córnea, segundo os momentos de avaliação (em dias) e grupos

\begin{tabular}{clccc} 
& & & \multicolumn{3}{c}{ Medida } \\
\cline { 3 - 5 } Momento & Grupo & Periferia & Ponto médio & Central \\
\cline { 3 - 5 } & GC & $0,00(0,00 ; 12,27) \mathrm{A}$ & $0,00(0,00 ; 0,00) \mathrm{A}$ & $0,00(0,00 ; 0,00) \mathrm{A}$ \\
M1 & GT & $0,00(0,00 ; 14,92) \mathrm{A}$ & $0,00(0,00 ; 0,00) \mathrm{A}$ & $0,00(0,00 ; 0,00) \mathrm{A}$ \\
& GL5 & $6,40(0,00 ; 9,46) \mathrm{A}$ & $0,00(0,00 ; 0,00) \mathrm{A}$ & $0,00(0,00 ; 0,00) \mathrm{A}$ \\
& GL3 & $7,96(0,00 ; 14,41) \mathrm{A}$ & $0,00(0,00 ; 0,00) \mathrm{A}$ & $0,00(0,00 ; 0,00) \mathrm{A}$ \\
\hline \multirow{4}{*}{ M2 } & GC & $15,69(11,64 ; 34,26) \mathrm{B}$ & $17,62(8,88 ; 38,77) \mathrm{B}$ & $0,00(0,00 ; 22,38) \mathrm{A}$ \\
& GT & $17,38(10,75 ; 21,86) \mathrm{B}$ & $16,07(7,56 ; 35,07) \mathrm{B}$ & $9,18(0,00 ; 24,03) \mathrm{A}$ \\
& GL5 & $26,77(17,23 ; 34,35) \mathrm{B}$ & $13,63(9,72 ; 22,93) \mathrm{B}$ & $0,00(0,00 ; 19,99) \mathrm{A}$ \\
& GL3 & $24,10(8,64 ; 30,70) \mathrm{A}$ & $15,56(5,74 ; 21,23) \mathrm{B}$ & $0,00(0,00 ; 25,17) \mathrm{A}$ \\
\hline
\end{tabular}

Letras maiúsculas comparam os momentos dentro do mesmo grupo, duas medianas seguidas de uma mesma letra maiúscula não se diferem $(\mathrm{P}>0,05)$. GC - Grupo Controle, GT - Grupo Tween, GL5 - Grupo Citrus lemon 5\% e GL3 - Grupo Citrus lemon 3\%.

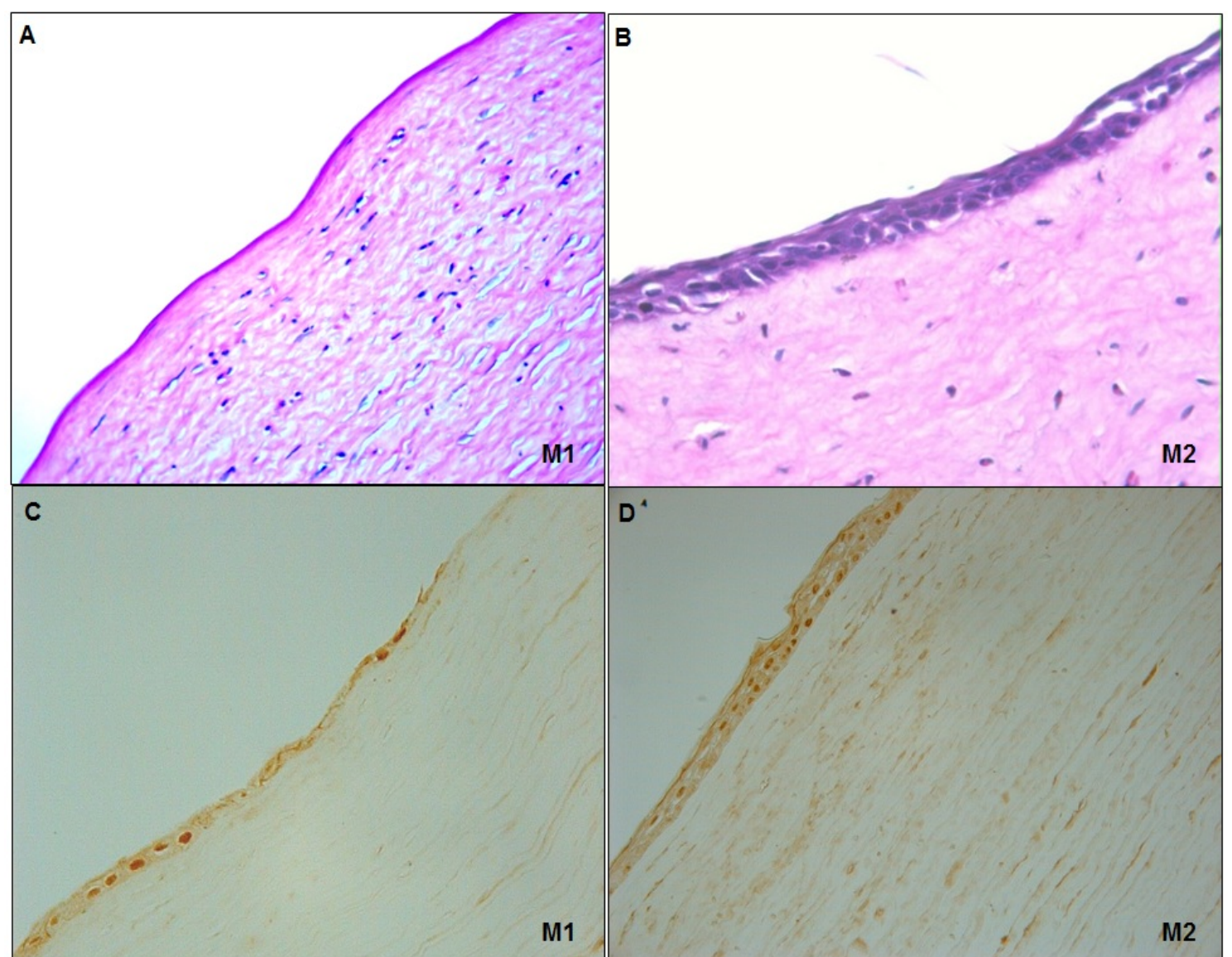

Figura 1. (A) Região da periferia corneal de coelho do Grupo Citrus lemon 5\% no M1, notar ausência de epitélio, estroma sem lesões e com infiltrado inflamatório. (B) Região corneal central de coelho do Grupo Citrus lemon 5\% do M2, observar a completa reepitelização e diminuição da celularidade em relação a A (Coloração HE - obj. 400x). (C) e (D) Cortes histológicos de córnea de coelhos do Grupo Citrus lemon $3 \%$, submetidos à imunomarcação para PCNA. Observar a presença de células epiteliais em proliferação (células com o núcleo marrom escuro), dispostas em uma camada incompleta no M1 e notar a reepitelização completa e a presença de células em proliferação no M2 (obj. 400x). 
Avaliação histomorfométrica...

Tabela 2. Mediana e valores mínimos e máximos do número total de células epiteliais segundo grupo e momento de avaliação

\begin{tabular}{lcc} 
& \multicolumn{2}{c}{ Momento de avaliação } \\
\cline { 2 - 3 } Grupo & $(\mathrm{M} 1) 1$ dia & $(\mathrm{M} 2) 5$ dias \\
\hline GC & $107,5(0,00 ; 268,00) \mathrm{A}$ & $465,5(328,00 ; 856,00) \mathrm{B}$ \\
GT & $67,0(0,00 ; 170,00) \mathrm{A}$ & $728,0(408,00 ; 1377,00) \mathrm{B}$ \\
GL5 & $22,5(0,00 ; 124,00) \mathrm{A}$ & $635,5(507,00 ; 807,00) \mathrm{B}$ \\
GL3 & $118,0(0,00 ; 446,00) \mathrm{A}$ & $559,0(410,00 ; 706,00) \mathrm{A}$ \\
\hline
\end{tabular}

Letras maiúsculas comparam os momentos dentro do mesmo grupo, duas medianas seguidas de uma mesma letra maiúscula não se diferem ( $\mathrm{P}>0,05)$. GC - Grupo Controle, GT - Grupo Tween, GL5 - Grupo Citrus lemon 5\% e GL3 - Grupo Citrus lemon 3\%.

A imunomarcação celular para PCNA foi evidenciada apenas no epitélio da córnea e foi observado em todos os cortes histológicos portadores do mesmo (Fig. 1). Observou-se aumento significativo da divisão e multiplicação das células epiteliais no M2 dos grupos GC, GT e G5, em relação ao M1 (Tab. 3).

Tabela 3. Mediana e valores mínimos e máximos da porcentagem de células marcadas para PCNA, segundo grupo e momento de avaliação

\begin{tabular}{lcc} 
& \multicolumn{3}{c}{ Momento de avaliação } \\
\cline { 2 - 4 } Grupo & $($ M1 $) 1$ dia & $($ M2) 5 dias \\
\hline GC & $7,79(0,00 ; 10,00) A$ & $18,02(14,33 ; 24,26) B$ \\
GT & $2,35(0,00 ; 11,19) \mathrm{A}$ & $17,06(12,93 ; 22,51) \mathrm{B}$ \\
GL5 & $4,03(0,00 ; 20,00) \mathrm{A}$ & $23,81(11,44 ; 26,15) \mathrm{B}$ \\
GL3 & $7,60(0,00 ; 30,27) \mathrm{A}$ & $23,36(15,99 ; 41,08) \mathrm{A}$ \\
\hline
\end{tabular}

Letras maiúsculas comparam os momentos dentro do mesmo grupo, duas medianas seguidas de uma mesma letra maiúscula não se diferem (P>0,05). GC - Grupo Controle, GT - Grupo Tween, GL5 - Grupo Citrus lemon 5\% e GL3 - Grupo Citrus lemon 3\%.

\section{DISCUSSÃO}

O óleo essencial de Citrus lemon é uma mistura complexa de compostos voláteis (Aloisi et al., 2002; Cecarelli et al., 2004) com reconhecidas propriedades biológicas (Baser e Buchbauer, 2009). Os seus principais componentes são terpenos (Bakkali et al., 2008), que, dentre as substâncias encontradas na natureza, constituem o principal composto químico com atividades antiulcerogênicas (Lewis e Hanson, 1991). Esse produto natural já foi utilizado com êxito em estudos com úlceras gástricas em ratos (Rozza et al., 2011), entretanto não foram encontrados relatos do seu uso na oftalmologia e mais especificamente no tratamento de úlceras de córnea, que estão entre as doenças oculares mais comuns no atendimento oftalmológico veterinário.

Nos cortes histológicos avaliados, todas as córneas apresentavam o estroma íntegro, com variação apenas da sua celularidade, que era representada por ceratócitos em pequena quantidade e células inflamatórias em número variado. As células epiteliais que se apresentavam em processo de divisão e migração em direção ao centro da córnea provavelmente eram originárias da camada basal do epitélio do limbo que, na ausência do epitélio corneal, possuem capacidade de proliferação e de transformarem-se em células epiteliais da córnea, contribuindo para a sua reparação (Yew et al., 2000).

O epitélio apresenta grande capacidade de regeneração; assim, após uma lesão, as células entram em mitose e deslizam em direção ao centro da córnea, preenchendo o defeito (Gilger et al., 2007). Esse mesmo padrão de cicatrização pôde ser constatado no processo de reparação das córneas estudadas, já que no primeiro momento de avaliação, após um dia do procedimento cirúrgico, observaram-se células epiteliais apenas na periferia corneal e somente em alguns cortes histológicos; enquanto no período final de 
avaliação, após cinco dias, notou-se a presença de epitélio recobrindo todo o estroma, ou apenas a periferia e ponto médio corneal.

No M1, todos os grupos apresentaram pelo menos um animal com epitélio na periferia corneal, sendo que o GL3 e o GL5 apresentaram os maiores valores de mediana de altura epitelial, $7,96 \mu \mathrm{m}$ e $6,4 \mu \mathrm{m}$, respectivamente; enquanto nos demais grupos observou-se mediana zero. Além disso, foram os grupos que continham maior número de animais apresentando epitélio, com quatro animais no GL5 e três no GL3. Embora não comprovada a diferença na análise estatística, esses bons resultados podem sugerir possível efeito positivo sobre a proliferação celular do óleo essencial de Citrus lemon, o que também foi observado por Rozza et al. (2007) no tratamento de úlceras gástricas de ratos.

Nenhum grupo do M1 apresentou epitélio no ponto médio e central corneal devido às características da reparação corneal associada ao tempo de evolução, que, segundo Yew et al. (2000), após a completa remoção do epitélio corneal de coelhos, as primeiras células em mitose podem ser observadas no epitélio do limbo decorridas 12 horas do debridamento epitelial. Se ocorrer a remoção do epitélio e parte do estroma por ceratectomia fotorefrativa, a divisão celular inicia-se após 24 horas e é observada primeiramente nas células epiteliais das bordas da lesão (Gan et al., 2001). Portanto, na primeira avaliação, com apenas 24 horas da cirurgia, é possível encontrar células epiteliais somente na região da periferia corneal.

No segundo momento de avaliação (após cinco dias), os animais de todos os grupos apresentaram epitélio na periferia e ponto médio da córnea. O GL5 e GL3 novamente foram os grupos com as maiores medianas na periferia corneal, obtendo $26,77 \mu \mathrm{m}$ e $24,1 \mu \mathrm{m}$, respectivamente, o que corresponde à altura normal do epitélio corneal, que, segundo Samuelson (2007), pode variar de 25 a $40 \mu \mathrm{m}$. No ponto médio corneal, os valores das medianas dos grupos foram similares, enquanto na região central o GT foi o único grupo em que a mediana não foi nula, obtendo $9,18 \mu \mathrm{m}$ de altura epitelial no centro da córnea. Assim como no primeiro momento de avaliação, no M2, os grupos tratados com colírio de Citrus lemon nas concentrações 3 e $5 \%$ mostraram uma tendência, não significativa, ao estímulo da proliferação celular; o que talvez possa ser comprovado em estudos com um número maior de animais. Além disso, o tratamento com Tween também demonstrou resultados similares aos do grupo controle, ou seja, ausência de reações adversas, o que permite a manutenção de sua utilização como diluente do colírio de citrus sem que ocorra comprometimento da reepitelização corneal.

$\mathrm{Na}$ análise estatística, ao se compararem os momentos, no M2 os grupos GC, GT e GL5 apresentaram um aumento com significância da altura epitelial na periferia da córnea. No GL3 esse padrão não foi verificado, possivelmente devido à maior mediana apresentada no M1, e consequentemente menor aumento relativo da sua altura epitelial, embora a sua mediana tenha sido uma das maiores no M2 também. No ponto médio, todos os grupos apresentaram a altura epitelial significativamente maior, já que no primeiro momento nenhum animal continha células epiteliais nessa região.

Por meio da imuno-histoquímica para PCNA, que é um valioso marcador de mitose celular (Gan et al., 1999), pôde-se notar, no M1, que os animais com as maiores porcentagens de células em divisão pertenciam aos grupos tratados com colírios de óleo essencial de Citrus lemon, chegando até a 30,27\% em um animal do GL3, enquanto nos grupos GC e GT as maiores porcentagens de cada um foram, respectivamente, 10 e $11,19 \%$. Porém, considerando-se as medianas, os grupos com os melhores resultados foram o controle e o GL3. Essa alta porcentagem de células em divisão nos grupos tratados com óleo essencial de limão pode, provavelmente, ser decorrente do efeito positivo na estimulação da proliferação celular, o que também pôde ser observado na avaliação da altura epitelial da periferia corneal no primeiro momento de avaliação.

Os grupos GC, GT e GL5 mostraram aumento na taxa de mitose celular no $\mathrm{M} 2$ em relação ao primeiro momento de avaliação. $\mathrm{O}$ grupo tratado com colírio de óleo essencial de limão a 3\%, embora tenha apresentado uma das maiores medianas no $\mathrm{M} 2$, não demonstrou um aumento com significância provavelmente por ter apresentado animais com alta taxa de divisão celular logo no primeiro dia de avaliação, conforme já apresentado anteriormente. 
Após 24 horas do procedimento cirúrgico e no período final de avaliação, todos os grupos apresentaram valores similares para a celularidade encontrada na córnea, sendo representada por algumas células epiteliais, ceratócitos e células inflamatórias, que se infiltram no estroma após lesão corneal (Gilger et al., 2007). Segundo Gan et al. (1999), a presença de leucócitos aumenta a expressão de PCNA, favorecendo a proliferação celular e diminuindo o tempo de cicatrização.

O óleo essencial de Citrus lemon é um produto natural, disponível mundialmente, com propriedades biológicas a serem exploradas no tratamento de doenças oculares. Ressalta-se que nosso grupo de pesquisa iniciou a utilização desse produto em oftalmologia, devendo-se estimular trabalhos posteriores com maiores complexidades na metodologia que permitam a sua avaliação em um número maior de animais, assim como em úlceras profundas ou contaminadas.

\section{CONCLUSÃO}

Os colírios à base de óleo essencial de Citrus lemon, nas diferentes concentrações, promoveram a reepitelização corneal, sem causar lesões adicionais ao epitélio ou estroma, podendo ser utilizado na superfície corneal para o tratamento de ceratites ulcerativas.

\section{AGRADECIMENTOS}

À FAPESP (Fundação de Amparo à Pesquisa do Estado de São Paulo) pelo apoio financeiro.

\section{REFERÊNCIAS}

ALOISI, A.M.; CECCARELLI, I.; MASI, F.; SCARAMUZZINO, A. Effects of the essential oil from Citrus lemon in male and female rats exposed to a persistent painful stimulation. Behav. Brain Res., v.136, p.127-135, 2002.

BAKKALI, F.; AVERBECK, S.; AVERBECK, D.; IDAOMAR, M. Biological effects of essential oils - a review. Food Chem. Toxicol., v.46, p.446-475, 2008.

BASER, K.H.C.; BUCHBAUER, G. Handbook of essential oils: science, technology and applications. Boca Raton: CRC Press, 2009. 991p.
CECCARELLI, I.; LARIVIERE W.R.; FIORENZANI P.; SACERDOTE P.; ALOISI A.M. Effects of long-term exposure of lemon essential oil odor on behavioral, hormonal and neuronal parameters in male and female rats. Brain Res., v.1001, p.68-86, 2004.

FISHER, K.; PHILLIPS, C.A. The effect of lemon, orange and bergamot essential oils and their components on the survival of Campylobacter jejuni, Escherichia coli O157, Listeria monocytogenes, Bacillus cereus and Staphylococcus aureus in vitro and in food systems. J. Appl. Microbiol., v.101, p.1232-1240, 2006.

GAN, L.; FAGERHOLM, P.; KIM, H.J. Effect of leukocytes on corneal cellular proliferation and wound healing. Invest. Ophthalmol. Vis. Sci., v.40, p.575-581, 1999.

GAN, L.; HAMBERG-NYSTRÖM, H.; FAGERHOLM, P.; SETTEN, G.V. Cellular proliferation and leukocyte infiltration in the rabbit cornea after photorefractive keratectomy. Acta Ophthalmol. Scand., v.79, p.488-492, 2001.

GILGER, B.C.; BENTLEY, E.; OLLIVIER, F.J. Diseases and surgery of the canine cornea and sclera. In: GELATT, K.N. Veterinary ophthalmology. 4.ed. Iowa: Blackwell Publishing, 2007. p.690-752.

JOHNSON, R.A.; WICHERN, D.W. Applied multivariate statistical analysis. 5.ed. New Jersey: Prentice-Hall, 2002. 767p.

LEWIS, D.A.; HANSON, P.J. Anti-ulcer drugs of plant origin. Prog. Med. Chem., v.28, p.201$231,1991$.

MORAES, T.M.; KUSHIMA, H.; MOLEIRO, F.C. et al. Effects of limonene and essential oil from Citrus aurantium on gastric mucosa: role of prostaglandins and gastric mucus secretion. Chem. Biol. Interac., v.180, p.499-505, 2009.

ROZZA, A.L.; MORAES, T.M.; KUSHIMA, H. et al. Gastroprotective mechanisms of Citrus lemon (Rutaceae) essential oil and its majority compounds limonene and $\beta$-pinene: Involvement of heat-shock protein-70, vasoactive intestinal peptide, glutathione, sulfhydryl compounds, nitric oxide and prostaglandin E2. Chem. Biol. Interac., v.189, p.82-89, 2011. 
ROZZA, A.L.; ORTIZ, M.; HIRUMA-LIMA, C.A.; PELLIZZON, C.H. Healing activity of Citrus lemon (Rutaceae) fruit barks essential oil on gastric ulcer in rats: morphological and ultrastructural studies. In: CONGRESO ITALOLATINOAMERICANO DE ETNOMEDICINA, 16., 2007, La Plata. Anais... La Plata: Cajar, 2007. p.341-342.

SAMPAIO, R.L., RANZANI, J.J.T.; JÚNIOR, V.R. et al. Aspectos clínicos e imunopatológicos da ceratoplastia com membrana amniótica xenógena fresca e conservada em glicerina. Estudo experimental em coelhos. Arq. Bras. Med. Vet. Zootec., v.58, p.1077-1085, 2006.
SAMUELSON, D.A. Ophthalmic anatomy. In: GELATT, K.N. Veterinary ophthalmology. 4.ed. Iowa: Blackwell Publishing, 2007. p.37-148.

YEW, D.T.; LAM, T.K.; TSANG, D. et al. Changes of cytochemical markers in the conjunctival and corneal epithelium after corneal debridement. Cell. Mol. Neurobiol., v.20, p.465482, 2000.

ZAR, J.H. Bioestatistical analysis. 5.ed. New Jersey: Prentice Hall, 2009. 994p. 